\title{
Bilkis gazelle in Yemen - status and taxonomic relationships
}

\author{
Arnaud Greth, Douglas Williamson, Colin Groves, Georg Schwede and \\ Marc Vassart
}

Bilkis gazelle Gazella bilkis was first described in 1985 from material collected in Yemen in 1951. No new information about the species has been forthcoming since then and the animal's current status is uncertain in two respects. First, it is difficult to establish the taxonomic relationship between $\mathrm{G}$. bilkis and a possible subspecies of the Arabian gazelle, G. gazella erlangeri, which also occurs in the south-west Arabian peninsula. Secondly, uncontrolled hunting and the general lack of conservation measures in Yemen mean that, if it does still survive, its continued existence is far from assured. Systematic field surveys and taxonomic research are urgently needed to clarify the status of this animal and draw up conservation measures.

\section{Introduction}

Given the rate at which tropical forests are being destroyed, it is relatively easy to understand how cryptic rain-forest invertebrates with miniscule ranges can become extinct without being known to science, but it is startling to realize that a similar fate could befall the Bilkis gazelle Gazella bilkis, a mediumsized antelope in the Arabian peninsula.

Bilkis gazelle was described by Groves and Lay (1985) from museum specimens collected in Yemen in 1951 and named in honour of the Queen of Sheba. No further material or information has been forthcoming since 1951 and there is none known in captivity. To comprehend fully the problems regarding G. bilkis, an overview of other gazelle taxa in the Arabian peninsula is necessary. The taxonomic issue is confused by the presence of another poorly understood gazelle in the same region $G$. gazella erlangeri, which is believed to be a subspecies of the mountain gazelle.

In 1987, Ryder emphasized the 'urgent need for conservation action' for some gazelle species. The situation has recently improved in the north of the Arabian peninsula for the sand gazelle G. subgutturosa marica and the mountain gazelle G. g. gazella (Thouless et al.,
1991) but at least three other subspecies of $G$. gazella as well as Bilkis gazelle are still in jeopardy. Because information on all the gazelles is either very scarce or non-existent, it is very difficult to plan conservation measures. Priority should, therefore, be given to taxonomic studies and field surveys in order to formulate and initiate a conservation strategy, as well as immediate remedial action.

This paper presents all available information on Bilkis gazelle and emphasizes the urgency of undertaking field surveys and taxonomic research to clarify its status and facilitate its conservation.

\section{Gazella bilkis and the dark forms of $G$. gazella in the southern Arabian peninsula}

\section{Taxonomy}

The taxonomy of the genus Gazella is considered to be one of the most equivocal among mammal groups (Groves and Harrison, 1967). The classification was modified recently, changing the status of some taxa from subspecies to species (Groves, 1969; Furley et al., 1988), but taxonomic relationships between 
and within a number of species are still unclear.

Groves and Lay (1985) described G. bilkis from five specimens (skins and skulls) deposited in the Field Museum of Natural History in Chicago by H. Hoogstraal in 1951, and one skull presented to the Natural History Museum, London, by W. T. Blanford in 1869 . According to these authors, a number of features of the skull, including the shape of the horns (straight with 12-15 rings in the male, long with clearly developed rings in the female), and the morphology of teeth, nasal and premaxillary bones clearly differentiated bilkis from other species of gazelles. The colour patterns were also distinct: the body was very dark with paler fur on the flanks, haunches and legs, there was a very thick flank stripe, black and conspicuous in the field, and a white line on the inside of the thigh continuing down the shank. As a diagnostic feature, the bilkis gazelle is the darkest species of the genus.

At least three other species of gazelles, $G$. subgutturosa, G. saudiya and G. gazella (Groves and Harrison, 1967) were widely distributed throughout the Arabian peninsula. They will be discussed here briefly to make a clear distinction between the two taxa with which we are mainly concerned. The Arabian sand gazelle G. subgutturosa marica cannot be mistaken for any other species, being very pale in colour and living in sandy areas (Groves, 1989). The so-called 'Arabian dorcas' gazelle G. saudiya, probably either on the verge of extinction or already extinct in the wild, is small and sandy-brown in colour with long, straight horns in both sexes (Groves, 1989). Increasingly, it has been suggested that this gazelle is a distinct species, unrelated to African dorcas gazelles (Groves, 1989); recent cytogenetic studies strongly corroborate this (Rebholz et al., 1991), but it is still under investigation.

The situation of the mountain gazelle $G$. gazella is more complicated, because four subspecies occur in the south of the Arabian peninsula (Figure 1). One, G. g. cora, which is reported to be sympatric with $G$. bilkis (Groves, 1989), can be distinguished from it by the paler coat, as well as by many skull characteristics (Groves and Lay, 1985). A second subspecies, G. g. farasani (Thouless and Al Bassri, 1991), is restricted to the coral archipelago of Farasan, $30 \mathrm{~km}$ north of the Yemen border in the Red Sea (Figure 1). A third, G. $g$. muscatensis, with a pronounced dark grey coat (Groves, 1989), is restricted to the coastal strip of northern Oman (Figure 1).

The fourth subspecies, G. g. erlangeri (Groves et al., in prep.), is more controversial from a taxonomic point of view and its differentiation from G. bilkis is still unclear. It can be distinguished from G. g. cora by its small size and dark colour. Described by Neumann (1906) as G. arabica erlangeri from Lahej, north of Aden, based on a coloured plate (pl. 59) in Sclater and Thomas (1898), and recently resurrected as G. g. erlangeri (Groves et al., in prep.), this taxon is possibly sympatric with G. bilkis; two specimens from Ma'bar, Yemen (14 ${ }^{\circ} 46^{\prime} \mathrm{N}$, $44^{\circ} 21^{\prime} \mathrm{E}$ ), in the Field Museum of Natural History, Chicago, recorded by Groves and Lay (1985) as G. g. cora, are more likely to be G. g. erlangeri. Although Groves and Lay (1985) proposed that these two taxa are not conspecific because of probable sympatry and different morphological patterns, scientific evidence is still too weak to classify them as two distinct taxa. Cytogenetics and molecular techniques are necessary to clarify the picture.

Chromosome studies of G. g. cora and G. g. erlangeri have shown that both subspecies have 34 chromosomes in females and 35 in males. These numbers are identical to the ones found in G. g. gazella (Wahrman et al., 1973), confirming that these two taxa should be considered as subspecies of G. gazella. Blood enzyme studies on G. g. gazella, G. g. cora, G. g. erlangeri and G. 8. farasani also showed that these taxa are closely related (Vassart et al., in press).

G. gazella has a large phenotypic variability and some subspecies in Israel and Iran have not yet been described (Karami and Groves, 1992; Mendelssohn et al., in press). Special attention should be paid to the taxnomy of this species to allow a clear distinction of taxonomic units and to adopt the appropriate conservation measures. 


\section{Biological information}

There is almost no information available on the biology and distribution of G. bilkis. All the specimens collected in 1951 came from the mountainous area of $\mathrm{Ta}^{\prime} \mathrm{izz}\left(13^{\circ} 35^{\prime} \mathrm{N}, 44^{\circ} 02^{\prime} \mathrm{E}\right)$, $200 \mathrm{~km}$ south of Saana (Figure 1). Localities include El Hauban in Wadi Maleh, Usaifira and Jabal Zarba (Groves and Lay, 1985; Harrison and Bates, 1991). They were either solitary or in small groups on euphorbia-covered slopes, which were separated from cultivated areas by hills (Sanborn and Hoogstraal, 1953). No other biological data or photographs have been published. A limited survey was carried out in February 1992 by A.G. in the mountains (Jebbel Sabir, Jebbel Samah) between Ta'izz and Al Thurbah, $50 \mathrm{kms}$ to the south. Neither gazelles nor signs of their presence were found. Photographs of gazelles were shown to at least 100 local people in all the villages visited. All replied that gazelles had not been seen in the area for several decades.

It has been suggested that G. bilkis is endemic to Yemen (Groves and Lay, 1985), but no systematic field survey of its range has ever been conducted, and, considering the biogeography of the Asir mountain range and the regional distribution of other species, such as $G$. g. cora, it is possible that it occurred or even still exists in Saudi Arabia, at least in the south (Groves, 1989).

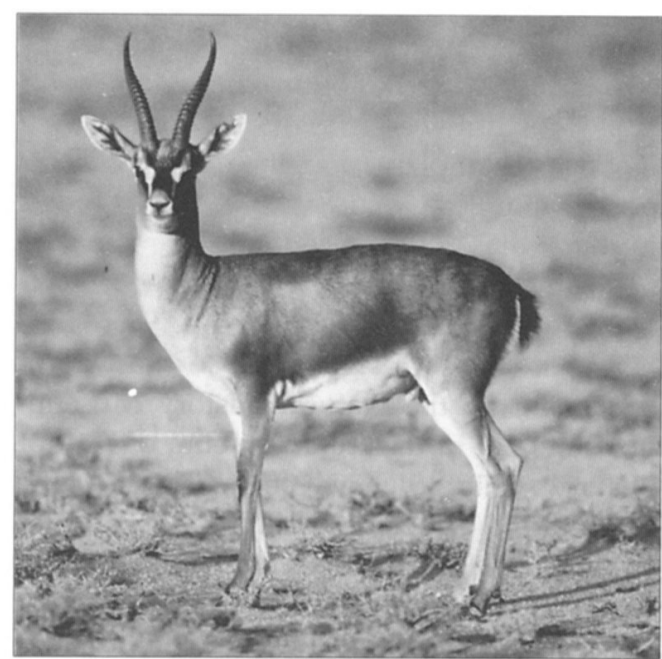

Gazella gazella erlangeri male kept at the NWRC (S. Saustier/NWRC).

No known captive population of G. bilkis exists in the world. Chester and Marwell zoos in UK maintain small groups of gazelles, which may include some individuals descended from G. g. cora and G. g. erlangeri hybridized with G. bilkis. A small group (identified from photographs by C. G.) was kept in Qatar in Sheik Al-Thani's collection (Al Wabra, near Shahaniyah) but they all died without issue.
Figure 1. Presumed range of the different subspecies of $G$. gazella (a. G. g. farasani) and of G. bilkis

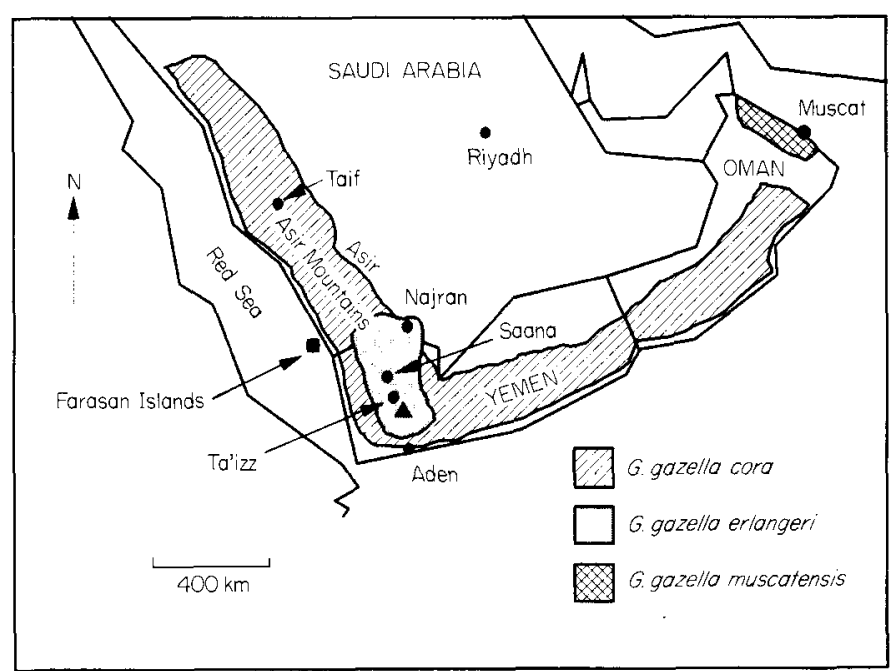


There is almost no information available for G. g. erlangeri. According to local bedouins, two forms of gazelles occur in the Asir mountains in south-west of Saudi Arabia and the nearby coastal plain, the Tihama (M. Shobrak, pers. comm.). One, called 'idmi' is light brown in colour and is almost certainly G. g. cora. The other one, smaller and darker, is probably $G$. g. erlangeri (Groves et al., in prep.). There have been no recent sightings of this form. Specimens in the Natural History Museum, London, and in the Field Museum of Natural History, Chicago, have been collected near Aden or Ta'izz (Yemen) and near Taif (Saudi Arabia). One farmer reported that in 1992 he regularly hunted small gazelles the colour of volcanic stones' near Lahej. This information corresponds with Neumann's (1906) description of gazelles caught in the same area. Animal dealers from Saudi Arabia or bedouins say that these gazelles are still often caught in Yemen, in the area between Najran and Sa'dah, near the border of Yemen and Saudi Arabia (Figure 1).

While no captive population exists of $G . g$. erlangeri outside the Middle East, this gazelle can still be found in reasonable numbers in captivity, particularly in Saudi Arabia. Their docile disposition makes them popular as pets and $G$. g. erlangeri is one of the most common gazelle species in the numerous private collections in the Kingdom. The illegal trade in these animals, which probably come from Yemen or from southern Saudi Arabia, indicates that this subspecies still occurs somewhere in good numbers in the wild. In 1991, a herd of 25 gazelles was found in a pet shop in Jeddah, called 'Beautiful Creatures'. According to the owner, the animals came from a location near Aden. Since then, other groups have been seen regularly in this shop. In 1987 a small captive herd was created at the National Wildlife Research Center (NWRC) with three individuals (one male, two females) given by the Emir of Najran. They are reported to be from an area in Yemen, close to the Saudi border. The herd was transferred to the King Khalid Wildlife Research Center (KKWRC) near Riyadh in January 1992. Nineteen individuals (11 males, eight females) were exchanged with private collections and added to the KKWRC herd during 1992.

\section{Conservation status}

The rich biological diversity and high level of endemism in the south-west Arabian peninsula contrasts with the lack of information on its natural history and conservation importance. A few ornithological expeditions have visited North Yemen since 1965 (Cornwallis and Porter, 1982) but none reported sightings of Bilkis gazelles and R. F. Porter (pers. comm.) saw no gazelles at all during six expeditions in North Yemen between 1979 and 1987.

The complete failure to locate Bilkis gazelles in the wild and the absence of conservation measures in Yemen indicate that if it survives at all its situation is desperate (unless G. bilkis and G. g. erlangeri are proved to be conspecific). Automatic rifles are widely available in Yemen and wildlife is generally over-hunted. During the visit of A. G. to Yemen in February 1992, some Yemeni people reported that relatives or farmers still regularly hunted gazelles in some places, such as the Lahej region and the Saham wadi, near Hoddeida. Moreover, the recent economic development of reunified Yemen following the discovery of oil is intensifying habitat degradation and causing a decline in wildlife.

\section{Questionnaire about dark forms of gazelles in Yemen}

To clarify the taxonomic relationships between G. bilkis and G. g. erlangeri and to collect biological information on these two taxa, a questionnaire and a set of colour prints of the G. g. erlangeri herd kept at the NWRC were sent to 25 people (10 antelope specialists, three Yemeni wildlife professionals, four people from the zoo community, three people in charge of conservation organizations in the Middle East and five others, including ornithologists, involved in surveys in Yemen). A note was also published in the Bulletin of the 
Two male Arabian sand gazelles (Gazella subgutturosa marica) fighting (A. Vareille/NWRC).

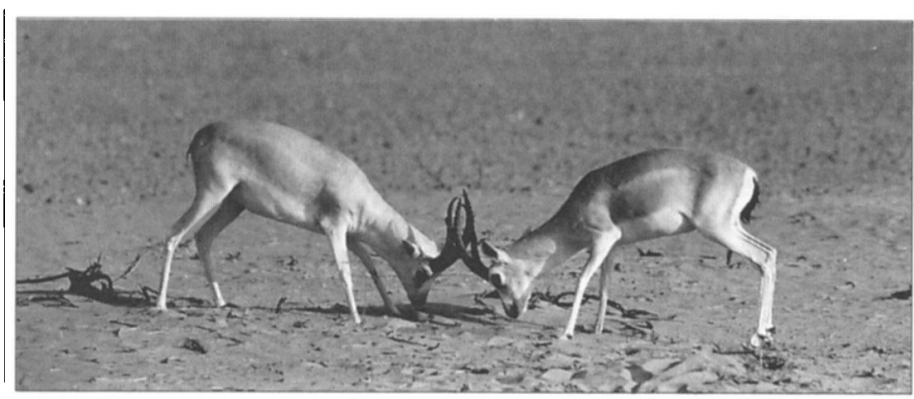

Ornithological Society of the Middle East (Greth, 1991) and in Gnusletter, which is published by the IUCN/SSC Antelope Specialist Group.

Of the 15 responses obtained 10 said they had no information. Of the five positive responses, two experts identified the gazelles on the prints as G. g. ssp., one as G. g. gazella, one as $G$. bilkis (for some of the pictures) and one as a mixed herd of G. gazella and G. bilkis. The phenotypic appearance of the NWRC herd is quite homogeneous. Even though the photographs sent for the inquiry were perhaps not of ideal quality for taxonomic identification, the contradictory answers obtained emphasize the taxonomic problems.

\section{Proposals and recommendations}

\section{Taxonomic research}

A joint effort should be made by geneticists, scientists involved in gazelle taxonomy, field researchers and zoo managers to apply modern genetic techniques on all available samples of the taxa discussed here. Allozyme and cytogenetic studies should provide valuable information. The best method may be the comparison of mitochondrial DNA, because the differentiation of the genome of the taxa concerned is probably relatively recent. This study should of course include G. bilkis and the different subspecies of G. gazella, with particular attention being given to $G$. $g$. erlangeri and G. g. muscatensis.

As a step towards this, Saudi Arabia's National Commission for Wildlife Conservation and Development (NCWCD) has initiated an innovative research project in collaboration with the University of California, La Jolla, San Diego, as well as other institutions. The main aim of this study is to clarify the taxonomic status of G. bilkis and G. g. erlangeri (and other taxa), by comparing DNA sequences in the hair of living specimens with the type specimens. If it is possible to extract DNA from the hairs of museum specimens several decades old, this study might help to determine relations between $G$. g. erlangeri and $G$. bilkis.

\section{Conservation action}

International conservation funds are needed urgently for a preliminary survey in Yemen. If $G$. bilkis or/and G. g. erlangeri is/are discovered, an ecological study should be conducted to define its/their distribution, habitat requirements, population status and the major threats. For both taxa, these studies should be concluded with a population and habitat viability analysis. It is also important to recall that the situation of G. g. cora is precarious in the Asir mountains and the coastal plains of the Tihama in Saudi Arabia (Thouless et al., 1991). Appropriate conservation measures should be urgently taken by implementing protected areas and enforcing hunting laws.

Although in situ conservation must remain the priority, the implementation of a captivebreeding programme in co-operation with the international zoo community and the concerned specialist groups (SSC/IUCN) should be considered for all relevant taxa. Individuals of non-viable populations could be captured to serve as founder stock.

All these activities should lead to the formulation of an integrated conservation action 
plan for the different gazelle taxa within 2 years, based on collaboration between regional governments and different international conservation institutions.

Assuming that Bilis gazelle still survives, its situation must be very precarious. To avoid a re-run of Operation Oryx, which in 1962 saved the last Arabian oryx by drastic and expensive measures, urgent steps need to be taken to study the dark forms of gazelle in Yemen and Saudi Arabia to provide a basis for planning their conservation.

\section{Acknowledgments}

The authors acknowledge with great respect and appreciation the work done by all the staff of the NCWCD for the conservation of gazelle species in the Arabian peninsula, and particularly HRH Prince Saud AI Faisal, who initiated all these efforts, and Professor A. Abuzinada, Secretary-General of the NCWCD. T. Abaigar, R. H. Daly, R. Estes, J. Kingdon, C. Magin, H. Mendelssohn, J. Newby and R. Porter helped us to gather information about the Bilkis gazelle. J. F. Asmode, J. Dolan, J. Grainger, L. Granjon, A. R. Khoja, N. Lindsay, F. Rietkerk, M. Shobrak gave useful information or comments on the early draft and helped finalize the proposals.

\section{References}

Cornwallis, L. and Porter, R.F. 1982. Spring observations on the birds of North Yemen. Sandgrouse, 4, 1-36.

Furley, C.W., Tichy, H. and Uerpmann, H.P. 1988. Systematic and chromosomes of the Indian gazelle, Gazella bennetti (Sykes, 1831). Z. Säugetierk, 53, 48-54.

Harrison, D.L. and Bates, P.J.J. 1991. The Mammals of Arabia. Harrison Zoological Museum Publications, Sevenoaks, England.

Greth, A. 1991. Gazelles in Yemen and Southern Saudi Arabia. Bulletin of the Ornithological Society of the Middle East, 27, Autumn, 39.

Groves, C.P. 1969. On the smaller gazelles of the genus Gazella de Blainville, 1816. Z. Säugetierk, 34, 38-60.

Groves, C.P. 1989. The gazelles of the Arabian peninsula. In Wildlife Conservation and Development in Saudi Arabia. Proceedings of First Symposium (eds A. H. Abuzinada, P. D. Goriup and I. A. Nader), pp. 237-248. NCWCD, Riyadh, Saudi Arabia.

Groves, C.P. and Harrison, D.L. 1967. The taxonomy of the gazelles (genus Gazella) of Arabia. J. Zool., Lond. 152, 381-387.
Groves, C.P. and Lay, D.M. 1985. A new species of the genus Gazella (Mammalia:Artiodactyla: Bovidae) from the Arabian peninsula. Mammalia, $49,27-36$.

Groves, C.P., Thouless, C. and Vassart, M. In press. Subspecies of Gazella gazella in Saudi Arabia. Fauna of Saudi Arabia.

Karami, M. and Groves, C.P. 1992. A mammal species new for Iran: Gazella gazella Pallas, 1766 (Artiodactyla, Bovidae). In Proceedings Ungulates '91' (eds F. Spitz, G. Janeau, G. Gonzalez and S. Aulagnier), pp. 361-364. SFEPM, Paris.

Mendelssohn, H., Yom-Tov, Y. and Groves, C.P. In press. Gazella gazella. Mammalian Species.

Neumann, O. 1906. Üeber einige Gazellen und KuhAntilopen. S. ber. Ges. naturf. Freunde Berlin, 237247.

Rebholz, W.E.R., Williamson, D. and Rietkerk, F. 1991. Saudi gazelle (Gazella saudiya) is not a subspecies of Dorcas gazelle. Zoo Biol. 10, 485-489.

Ryder, O.A. 1987. Conservation action for gazelles: An urgent need. Trends Ecol. Evol. 2, 143-144.

Sanborn, C.C. and Hoogstraal, H. 1953. Some mammals of Yemen and their ectoparasites. Fieldiana, Zool. 34, 229-252.

Thouless, C.R. and Al Bassri, K. 1991. Taxonomic status of the Farasan Island gazelle. I. Zool. Lond, 223, 151-159.

Thouless, C.R., Grainger, J.G., Shobrak, M. and Habibi, K. 1991. Conservation status of gazelles in Saudi Arabia. Biol. Conserv. 58, 85-98.

Vassart, M., Granjon, L., Greth, A. and Catzeflis, F.M. 1993. Genetic relationships of endangered Gazella species from the Arabian peninsula: an isozyme survey. Can. J. Zool., in press.

Wahrman, J., Richler, C., Goitein, R., Horowitz, A and Mendelssohn H. Multiple sex chromosome evolution, hybridization, and differential $X$ chromosome inactivation in gazelles. In Jerusalem Chromosome Conference, abstracts of additional papers and demonstrations. Chromosomes Today, 42, 434-435.

Arnaud Greth, 3 rue Larochelle, 75014 Paris, France. Georg Schwede and Marc Vassart, National Wildlife Research Center (National Commission for Wildlife Conservation and Development), PO Box 1086, Taif, Saudi Arabia.

Douglas Williamson, King Khalid Wildlife Research Center (National Commission for Wildlife Conservation and Development), PO Box 61681, Riyadh 11575, Saudi Arabia.

Colin Groves, The Australian National University, Department of Prehistory and Anthropology, GPO Box 4, Canberra, ACT 2601, Australia. 